\title{
Concordância nominal variável de número e saliência fônica: um estudo experimental*
}

\section{Variable nominal agreement and phonic salience: an} experimental study

\section{Cristina Azalim}

(NEALP, Universidade Federal de Juiz de Fora, Juiz de Fora, Minas Gerais, Brasil)

Mercedes Marcilese

(NEALP, Universidade Federal de Juiz de Fora, Juiz de Fora, Minas Gerais, Brasil)

Cristina Name

(NEALP, Universidade Federal de Juiz de Fora, Juiz de Fora, Minas Gerais, Brasil CNPq, Brasília, Distrito Federal, Brasil)

Lilian Scher

(NEALP, Universidade Federal de Juiz de Fora, Juiz de Fora, Minas Gerais, Brasil)

Lydsson Gonçalves

(NEALP, Universidade Federal de Juiz de Fora, Juiz de Fora, Minas Gerais, Brasil)

\section{RESUMO:}

O português brasileiro exibe um padrão variável de concordância de número em que se destacam duas regras principais: marcação redundante em todos os itens relacionados e, alternativamente, concordância não redundante, com marca obrigatória no determinante ou no pronome possessivo. A saliência fônica, uma propriedade vinculada ao contraste de material fônico quando comparadas as formas singular e plural de um dado item, tem sido apontada na literatura como

\footnotetext{
* A presente pesquisa está vinculada aos projetos Processamento de expressões quantificadas: explorando a relação entre língua e cognição numérica (CAAE: 26747214.6.0000.5147, com apoio da UFJF), e Interfaces internas e externas na aquisição e no processamento adulto de L1 e L2: concordância e tópico/foco no PB (CAAE: 44123015.6.0000.5147, financiado pela FAPEMIG). Ambos os projetos contam com a aprovação do comitê de ética da instituição.
} 
um fator relevante na alternância entre essas regras. Investigamos aqui experimentalmente o papel desse fator na realização morfofonológica da concordância nominal. Reportamos dois experimentos de produção eliciada conduzidos com falantes adultos, o primeiro utilizando nomes reais e o segundo pseudo-nomes. Os resultados revelam diferenças significativas em virtude da regra empregada - com tempos de reação maiores na condição não redundante - e não permitem sustentar um efeito de saliência nos termos em que esse fator é tradicionalmente caracterizado. A tonicidade da sílaba que carrega o morfema de plural parece ser, no entanto, relevante na alternância entre as regras.

Palavras-chave: Saliência fônica. Concordância nominal variável. Processamento linguístico. Variação linguística.

\section{ABSTRACT:}

Brazilian Portuguese exhibits a variable pattern of number agreement: redundant marks in all the related items, and, alternatively, nonredundant agreement, in which the plural mark is carried by the determiner or by the possessive being omitted in the remaining items. Phonic salience is a property related to the contrast between singular and plural forms of an item and had been raised as one of the relevant factors in agreement variation. In this paper the role of phonic salience is investigated by means of experimental methodology. We report the results of two elicited production experiments conducted with adult speakers - the first one, with real nouns, and second one with pseudonouns. The results are in line with the idea that the two rules of number agreement would be processed differently. Phonic salience, in turn, did not reveal a significant influence, contrary to the previous hypothesis. Nonetheless, syllable stress coincidence with the plural morpheme might be a cue for explaining the contrast between the two rules.

Keywords: Phonic salience. Variable nominal agreement. Language processing. Linguistic variation.

\section{Introdução}

No contexto de uma caracterização geral e sem filiação teórica específica, a concordância pode ser definida como: "o fenômeno gramatical no qual a forma de uma palavra numa sentença [ou em um sintagma] é determinada 
pela forma de uma outra palavra com a qual tem alguma ligação gramatical" (Trask 2004:61). Quando considerada essa definição, fica claro, no entanto, que o fenômeno assim caracterizado não se apresenta com a mesma extensão em todas as línguas naturais, já que, a depender da língua, nem todos os itens que apresentam relação gramatical entre si exibem necessariamente uma mudança de forma como resultado de tal relação. Por exemplo, no inglês, embora haja relação gramatical entre determinante (D), nome (N) e adjetivo (A), se compararmos os sintagmas The old book e The old books ("O livro velho" e "Os livros velhos", respectivamente), verificamos que não ocorre variação em $\mathrm{D}$ e em A em função da alternância entre singular e plural em N. No espanhol, por sua vez, ocorre alteração morfológica no artigo e no adjetivo em função do número e do gênero em $\mathrm{N}$. Assim sendo, temos El livro viejo ( $\mathrm{N}$ masculino singular - "O livro velho"), Los libros viejos (N masculino plural - "Os livros velhos") e La revista vieja (N feminino singular - "A revista velha"), Las revistas viejas ( $\mathrm{N}$ feminino plural - "As revistas velhas").

No que tange à concordância nominal e considerando pontualmente o português brasileiro (doravante, $\mathrm{PB}$ ) - focos do presente artigo - de acordo com Bechara (2015:554), trata-se daquela "que se verifica em gênero e número entre o adjetivo e o pronome (adjetivo), o artigo, o numeral ou o particípio (palavras determinantes) e o substantivo ou pronome (palavras determinadas) a que se referem". Entretanto, e na contramão da definição proposta por Bechara, padrões variáveis de concordância de número têm sido largamente atestados na língua, tanto no interior do sintagma nominal ${ }^{1}$ quanto no que diz respeito à relação entre sujeito e predicativo e, ainda, entre sujeito e verbo (cf.: Mendes; Oushiro 2015 para uma revisão recente da literatura).

De acordo com Labov (2003), um fenômeno pode ser caracterizado como variável quando registra frequências de variação acima de $5 \%$ e inferiores a $95 \%$. Por sua vez, um intervalo entre $95 \%$ e $99 \%$ de ocorrência de uma dada variante apontaria para uma regra de natureza semicategórica. No caso do PB, existe um consenso na literatura na caracterização da concordância - nominal e verbal - como um caso de variação (Scherre 2005, Scherre; Naro 2006, Mendes; Oushiro 2015, dentre outros); já no caso do português europeu, a concordância nominal seria uma regra categórica, enquanto a verbal tem sido caracterizada como decorrente de regras semicategóricas (Rubio 2015). No PB, duas regras

1. Abney (1987) defende que uma categoria funcional (D) faria parte da projeção estendida do NP (Nominal Phrase, sintagma nominal), postulando assim a caracterização do denominado sintagma determinante (do inglês Determiner Phrase, DP). Nesse sentido, o DP seria um sintagma composto por um elemento da categoria D na posição de núcleo e um NP como seu complemento. No entanto, não é muito comum encontrarmos o termo DP em trabalhos de orientação sociolinguística, nos quais se utiliza mais frequentemente o termo NP para fazer referência a estruturas de natureza nominal. Nesse sentido, faz-se necessário aqui esclarecer que, no presente artigo, adotamos a caracterização formulada por Abney e amplamente difundida no âmbito da Teoria Gerativa. Por outro lado, o termo NP será mantido quando forem discutidos trabalhos que utilizam preferencialmente tal denominação para fazer menção às estruturas nominais. Assim, em alguns momentos, ambos os termos podem ser utilizados como sendo intercambiáveis. 
gerais de codificação morfofonológica das relações de concordância podem ser identificadas:

(i) de um lado, a comumente denominada "concordância padrão", na qual ocorre marcação morfológica de plural redundante em todos os itens que compõem o sintagma, marcação essa que é reiterada ainda na desinência verbal e no predicativo;

(ii) de outro, a regra que aqui denominaremos de não redundante, de acordo com a qual, a marca explícita de plural é expressa obrigatoriamente em $\mathrm{D}$ ou no pronome possessivo (Poss), podendo ser omitida nos demais itens do sintagma, no verbo e no predicativo (Costa; Figueiredo 2006).

O presente estudo investiga o processamento adulto da concordância variável de número no âmbito do sintagma determinante (DP). Especificamente, exploramos experimentalmente o papel da variável saliência fônica na marcação morfofonológica da concordância de número no DP, bem como uma possível interação entre esse fator e a variável extralinguística nível de escolaridade.

Vale ressaltar que neste artigo utilizaremos as expressões concordância redundante e não redundante em lugar de "presença/ausência de concordância", mais difundidas na literatura, pelo fato de entendermos que a concordância é fundamentalmente uma relação de natureza sintática e que apresenta, como mencionado anteriormente, reflexos morfológicos em grau diverso. Assim, é importante lembrar que a ausência de expressão morfofonológica não pode ser diretamente vinculada à ausência de uma relação que é crucial para a gramaticalidade da sentença. Em virtude da atuação das regras anteriormente delimitadas, sentenças como (1-3) ilustram variantes presentes no PB (dados retirados do corpus de Molina, em prep.):

(1) Essas cores escuras são bonitas. (marcação redundante)

(2) Essas meninaØ não arrumaØ casa. (marcação não redundante)

(3) ...aØ minhas colegaØ vão ficar tudo com inveja. (marcação não redundante)

A alternância entre as regras de marcação morfológica redundante e não redundante no PB não é aleatória, mas - de acordo com numerosas pesquisas desenvolvidas no âmbito da Sociolinguística Variacionista - tal variação é condicionada pela atuação de fatores internos ou linguísticos e fatores extralinguísticos (Braga; Scherre 1976 apud Scherre 1988, Braga 1977, Scherre 1978, 1988). Dentre os fatores linguísticos tidos como relevantes na realização da concordância variável no interior do DP, encontramos: o contexto fonológico subsequente, o princípio da saliência fônica e o princípio do paralelismo formal, sendo que os dois últimos têm sido identificados como os mais importantes (Brandão 2013, Chaves 2014). 
A saliência fônica é uma propriedade definida em função do grau de contraste existente entre as formas singular e plural de um mesmo item lexical (comparar, por exemplo, os pares de nomes livro-livros e jornal-jornais). O princípio da saliência fônica, que será melhor desenvolvido mais à frente, estabelece que formas mais salientes teriam uma maior probabilidade de serem morfologicamente marcadas do que as menos salientes. Assim, esperase que nomes com maior grau de diferenciação de material fônico na relação singular/plural exibam morfologia redundante com mais frequência do que itens com menor diferenciação. De acordo com Chaves (2014), a saliência fônica é um fator de natureza morfofonológica apontado na literatura como uma das variáveis mais significativas no que diz respeito à alternância na marcação de número, tanto no âmbito do DP quanto na relação sujeito-verbo.

Apesar de a concordância nominal variável e o papel da saliência fônica na ocorrência desse fenômeno serem tópicos amplamente investigados, sobretudo numa perspectiva descritiva e com ênfase nos aspectos sociolinguísticos do fenômeno, o assunto está longe de ser esgotado. O presente artigo se insere numa perspectiva que investiga a dimensão cognitiva e perceptual da variação linguística, i.e., uma abordagem que busca compreender de que modo a variação linguística é percebida, representada e processada pelos falantes (CampbellKibler 2009, Squires 2014, Marcilese et al. 2015, dentre outros). Neste caso, nosso objetivo é investigar o papel da saliência fônica no processamento da concordância nominal variável no PB por meio de metodologia experimental e avaliar em que medida dados relativos à percepção e à produção se mostram compatíveis com o reportado previamente a partir de análise de corpora. Para tal, foram desenvolvidos dois experimentos de produção eliciada por repetição. No primeiro experimento foram utilizados nomes reais do PB mais e menos salientes; já no segundo experimento, foram criados pseudo-nomes respeitando o padrão fonotático da língua e mantendo a distinção entre itens mais e menos salientes. Na seção 2 retomamos um conjunto de estudos de cunho sociolinguístico que têm investigado o fenômeno em questão a partir da análise de corpora. Em seguida, apresentamos brevemente algumas propostas de análise formal que visam a dar conta da concordância no âmbito do DP no $\mathrm{PB}$, formuladas dentro do arcabouço gerativista. Na quarta seção, reportamos os experimentos conduzidos. Para concluir, tecemos as considerações finais e indicamos os desdobramentos futuros da pesquisa.

\section{Saliência fônica e concordância nominal variável}

Como vimos anteriormente, de acordo com a caracterização tradicional, na concordância nominal todos os itens relacionados apresentam marca de número: "o adjetivo em posição predicativa concorda com o sujeito em gênero e número; o adjetivo em posição atributiva, bem como os determinantes e 
quantificadores, concordam em gênero e número com o núcleo nominal da construção a que pertencem" (Xavier; Mira Mateus 1990:99). Embora essa descrição pareça indicar a existência de padrões gramaticais altamente estáveis e homogêneos, desde os anos de 1970, diversos estudos vêm apontando a existência de processos de mudança e variação linguística no $\mathrm{PB}$, vinculados ao modo como a concordância é morfofonologicamente codificada na língua (Braga 1977, Scherre 1988, Graciosa 1991, Vieira 1995, Almeida 1997, dentre muitos outros). Em virtude disso, nesta seção, trataremos do estudo da concordância nominal variável no PB focalizando o papel da saliência fônica sob a perspectiva da Sociolinguística.

O denominado princípio da saliência fônica foi formulado por Lemle e Naro (1976, 1977 apud Scherre 1978) e estabelece que formas mais salientes, considerando-se a diferenciação do material fônico na oposição singular/ plural, como em ovo [o]v[u] versus ovos [ว]v[us], são mais perceptíveis e, portanto, mais prováveis de serem marcadas no plural do que formas menos salientes, como em menin[u] - menin[us]. Assim, o maior ou menor contraste morfofonológico entre a forma singular e plural de um dado item seria relevante na ocorrência de marcação redundante ou não redundante.

As pesquisas investigando o papel da saliência fônica na realização das regras de concordância no sintagma nominal tiveram início de fato - antes mesmo da formulação do citado princípio - com o estudo de Braga e Scherre (1976 apud Scherre 1988), a partir da análise de dados de sete falantes residentes no Rio de Janeiro, de classes sociais, faixas etárias e procedências geográficas distintas. Os resultados desse estudo parecem sustentar a hipótese de que uma maior saliência fônica do item nominal favoreceria a ocorrência da regra de concordância redundante, enquanto uma menor saliência favoreceria a concordância não redundante. Os dados analisados por Braga e Scherre (1976 apud Scherre 1988) se revelaram compatíveis com a escala de saliência postulada pelas autoras (reproduzida na Tabela 1) em todos os grupos sociais considerados, embora a hierarquia de saliência pareça ter um papel mais expressivo nos dados das classes média e média alta. 
Tabela 1 - Escala hierárquica de saliência proposta por Braga e Scherre (1976 apud Scherre 1988) ${ }^{2}$

\begin{tabular}{|c|}
\hline 1) Plural duplo ou metafônico (olho, olhos); \\
\hline 2) Acréscimo de -S e mudança silábica (botão/botões, quartel/quarteis); \\
\hline 3) Acréscimo de -ES em palavras terminadas em -R (dor/dores); \\
\hline 4) Acréscimo de -S em palavras de plural regular (coisa/coisas). \\
\hline 5) Acréscimo de -ES em palavras terminadas em -S (vez/vezes). \\
\hline
\end{tabular}

Dando sequência a essas pesquisas pioneiras, um conjunto de estudos tem sido desenvolvido com o objetivo de investigar o papel dessa variável. Braga (1977) e Scherre (1978) pesquisaram a influência da saliência fônica em combinação com fatores extralinguísticos. Braga (1977) investigou a relação entre saliência e nivel social a partir de dados de sete falantes das classes média e baixa do Triângulo Mineiro. Scherre (1978), por sua vez, avaliou a relação entre saliência e nivel de escolarização a partir dos dados de dez falantes da área urbana do Rio de Janeiro (seis semi-escolarizados, alunos do Movimento Brasileiro da Alfabetização - MOBRAL), três universitários e um com 11 anos de escolarização). Esses estudos revelaram uma relação entre escolarização e realização da concordância: quanto mais escolarizados os informantes, maior a ocorrência de concordância redundante.

Outra pesquisa que explorou o papel da saliência fônica na realização da concordância nominal no PB foi conduzida por Guy (1981), avaliando o grau de diferenciação do material fônico entre singular/plural e a tonicidade. Nesse caso, foram considerados dados de falantes semi-escolarizados do Rio de Janeiro. Os resultados obtidos nesse estudo apresentam aspectos tanto divergentes quanto convergentes em relação ao trabalho de Scherre (1978), mencionado anteriormente. Considerando os diferentes graus na escala de saliência, na análise de Guy (1981), os itens terminados em -ÃO e em -L se assemelham aos itens regulares, desfavorecendo a marcação explícita de plural, em contraste com os itens terminados em -R ou -S no singular (do tipo vez, mês, etc.), que se mostraram mais propensos a preservar a marcação de plural. Diferentemente, os dados de Scherre (1978) sugerem que os itens terminados em -L e os terminados em -ÃO deveriam ocupar o segundo nível na escala da saliência, ou seja, seriam o segundo grupo de itens que mais favoreceriam a marcação explícita de

2. Como apontado por um dos avaliadores deste artigo, os níveis (3) e (5) dessa hierarquia também envolvem algum tipo de mudança silábica. Nesses dois casos temos um acréscimo de sílaba, enquanto em (2) há uma manutenção do número total de sílabas, mas ocorre uma alteração na forma da sílaba que carrega a marca de plural. Cabe reiterar que, na Tabela 1, estamos reproduzindo a hierarquia de saliência tal e como proposta originalmente por Braga e Scherre (1976). Faz-se necessário esclarecer que, apesar de estarmos tratando de saliência fônica e, portanto termos consciência de que uma representação fonológica dos itens analisados seria mais apropriada, optamos por manter aqui a caracterização nos moldes da proposta original das autoras. 
concordância. Já no que diz respeito aos itens terminados em -R e os terminados em -S no singular, os resultados de Guy (1981) se assemelham aos de Scherre (1978), visto que em ambos os trabalhos - considerando os dados de falantes semi-escolarizados - não foi constatada diferença estatística entre tais itens. Ainda, Guy (1981) defende que os itens oxítonos favorecem a concordância redundante, por terem acento na sílaba que recebe a marca de plural. A despeito das divergências apontadas, Guy (1981) conclui que seus dados são favoráveis à hipótese da saliência fônica, apesar de não se configurarem como provas decisivas do efeito de tal variável.

A partir de dados extraídos do banco de dados do Corpus Censo do $\mathrm{PEUL}^{3}$, Scherre (1988) também investigou a ocorrência de concordância nominal variável. Neste caso, os informantes foram distribuídos em dois grupos: (i) 48 adultos e (ii) 16 crianças. Cada grupo foi, por sua vez, subdividido em função de: (i) anos de escolarização; (ii) sexo e (iii) faixa etária. Nessa pesquisa, para fins de análise, foi considerada a saliência fônica sob as mesmas dimensões delimitadas por Guy (1981) - grau de diferenciação e tonicidade - acrescidas de uma terceira dimensão relativa ao número de sílabas dos itens. Sendo assim, foram consideradas as seguintes dimensões: (i) processos morfofonológicos de formação do plural; (ii) tonicidade da sílaba dos itens lexicais singulares e (iii) número de sílabas dos itens lexicais singulares. Especificamente no que tange aos processos morfofonológicos de formação do plural, Scherre (1988) propõe uma reformulação da escala inicialmente postulada por Braga e Scherre (1976 apud Scherre 1988) (cf.: Tabela 2), delimitando uma escala formada por seis níveis organizados do maior para o menor grau de saliência. Essa hierarquia foi considerada para a elaboração da nossa pesquisa experimental e, por esse motivo, será retomada na seção correspondente.

Tabela 2 - Hierarquia de saliência proposta por Scherre (1988)

(1) Plural duplo (papelzinho/papeizinhos);

(2) Acréscimo de -S e mudança silábica em palavras terminadas em -L (quartel/quarteis);

(3) Acréscimo de -S e mudança silábica em palavras terminadas em -ÃO (seleção/ seleções);

(4) Acréscimo de -ES em palavras terminadas em -R (cor/cores);

(5) Acréscimo de -ES em palavras terminadas em -S (vez/vezes; freguês/fregueses);

(6) Acréscimo de -S em palavras terminadas em vogal ou vogal + nasal, os chamados plurais regulares (irmão/ irmãos; lei/ leis). 
Como exposto até aqui, originalmente o conceito de saliência fônica está associado ao grau de diferenciação de material fônico no contraste singular/ plural de um mesmo item. Nesse sentido, diversos fatores podem contribuir para que um item na forma plural tenha maior ou menor "identidade fônica" quando comparado ao seu par singular. Estudos posteriores ao de Braga e Scherre (1976) levaram em consideração essa questão e foram incorporando dimensões à variável nas análises, tais como tonicidade da sílaba que recebe a marca de plural ou ainda número de sílabas dos itens analisados. A hierarquia de saliência apresentada na Tabela 2 traz uma caracterização da saliência em função dos processos morfológicos de formação de plural nos nomes. No entanto, se considerarmos as outras dimensões mencionadas, podem ser tecidas algumas considerações. Tomemos por exemplo as palavras mulher e papel, ambas nomes oxítonos. Na formação do plural de mulher, temos um acréscimo de sílaba $\left(m u_{-}\right.$ lher-mu_lhe_res) e um deslocamento da sílaba tônica. Com isso, a forma plural é paroxítona e o morfema de plural não coincide com a sílaba tônica. Já no nome papel, a formação de plural não altera o número total de sílabas e nem o padrão de acentuação da palavra. Assim, enquanto em mulher poderíamos pensar que o fato de haver um contraste no número de sílabas das formas singular e plural seria um fator que reforçaria a saliência do item plural (i.e., ele seria claramente distinto da forma singular), o fato de haver um deslocamento do acento pode diminuir essa saliência. Por outro lado, em papel, a marcação de plural recai na sílaba tônica, portanto, seria perceptualmente mais saliente. O padrão silábico dos itens seria, então, relevante na análise do contraste de material fônico entre formas singulares e plurais, já que esse padrão permite prever quais serão as mudanças introduzidas em cada caso.

A relevância da saliência fônica na realização da concordância nominal variável ainda hoje é alvo de discussão. Em trabalho recente, Lopes e Scherre (2012) avaliaram o efeito da saliência a partir de entrevistas de 50 a 60 minutos de duração com 32 falantes, moradores da cidade capixaba de Santa Leopoldina. Os informantes foram separados em grupos em função de três variáveis sociais: (i) sexo; (ii) escolaridade: Ensino Fundamental I e II; e (iii) faixa etária: 7-14, 15-25, 26-49 e maiores de 49 anos. Os dados coletados foram comparados com o reportado por Scherre (1988), Scherre e Naro (2006) e Silva (2011). Em conjunto, os resultados de todas as pesquisas até aqui mencionadas se mostram compatíveis com a ideia de que - quando considerados dados de produção espontânea ou semiespontânea - a variável saliência fônica exerce um papel crucial na realização da concordância nominal variável, visto que todos os trabalhos citados verificaram que os vocábulos classificados como [+salientes] se mostraram mais suscetíveis a receber a marca redundante de plural.

Entretanto, há estudos que vão na contramão das pesquisas reportadas até aqui. Campos (2015) avaliou a atuação do princípio da saliência fônica sobre a regra de pluralização dos elementos no DP a partir da análise de 15 
inquéritos do corpus mínimo do $\mathrm{NURC}^{4}$ e considerou as mesmas dimensões e subdivisões propostas por Scherre (1988). Ambos os estudos (Scherre 1988, Campos 2015) se assemelham por terem evidenciado a expressividade da dimensão tonicidade do item lexical no singular, bem como a irrelevância do fator "número de sílabas". Entretanto, os resultados reportados divergem entre si no que diz respeito à dimensão processos morfofonológicos de formação do plural. Enquanto os resultados de Scherre (1988) sugerem que essa dimensão exerce influência sobre a concordância de número, no estudo de Campos (2015), tal fator foi considerado irrelevante para a ocorrência do fenômeno. A análise do corpus mínimo do NURC sugere que os falantes cultos tendem a aplicar a regra de concordância redundante na língua falada, pluralizando os elementos do DP, independentemente do grau de saliência dos itens pluralizáveis.

Apesar de se tratar de um tópico bastante investigado na literatura sociolinguística, como apontado por Scherre (1988) e reforçado por Chaves (2014), o papel que a saliência desempenha na realização da concordância de número no PB ainda é foco de debates; afinal, os diversos estudos conduzidos sobre o tema nem sempre apresentam resultados convergentes. As diferenças encontradas recobrem aspectos distintos (cf.: Azalim 2016, para uma revisão detalhada). É possível encontrar discrepâncias, por exemplo, quanto às definições propostas para a variável (Lemle; Naro 1977 apud Scherre 1988, Naro; Lemle 1976 apud Scherre 1988), assim como também no que tange ao número de dimensões consideradas no estudo da saliência (Braga; Scherre 1976 apud Scherre 1988, Guy 1981, Scherre 1988). Além disso, a delimitação dos níveis que compõem a escala hierárquica de saliência fônica não é unanimemente compartilhada na literatura (cf.: Guy 1981, Lemle; Naro 1977 apud Scherre 1988, Scherre 1988). Há ainda autores que rejeitam parcial ou totalmente a relevância dessa variável, em virtude do observado na análise de dados (cf.: Nicolau 1984, 1995, Campos 2015). Em vista desses resultados controversos, a nossa pesquisa empírica visou a avaliar experimentalmente a dimensão relativa aos processos morfofonológicos de formação de plural, tomando como base a escala formulada por Scherre (1988) apresentada na Tabela 2.

Embora não represente o foco principal do presente trabalho, vale frisar que, além de fatores linguísticos como a saliência fônica, um conjunto de aspectos extralinguísticos também parecem influenciar a realização da concordância nominal de número no $\mathrm{PB}$, tais como: faixa etária, sexo, nível de escolaridade, local de origem/procedência, etc. De acordo com Brandão (2013), o nível de escolaridade do falante é o fator que sobressai nesse conjunto. A maioria dos estudos que têm analisado tal variável registrou um padrão sistemático de maior tendência ao uso de marcação redundante de plural por falantes com maior nível de escolaridade (Scherre 1988, Dias; Fernandes 2000, Brandão; Vieira 2012, 2013, dentre outros). A revisão bibliográfica apresentada 
reflete a relevância dessa variável, visto que a maioria dos referidos trabalhos tomam o grau de escolaridade como fator que atua em combinação com a variável saliência fônica no condicionamento da realização da concordância de número. Chamamos a atenção aqui para uma possível correlação entre nível de escolaridade e saliência fônica na realização da concordância nominal variável pelo fato de essa correlação ter sido investigada empiricamente no primeiro experimento conduzido (reportado na seção quatro deste artigo).

Cabe, no entanto, refletir sobre um ponto importante levantado por Oushiro (2015) a respeito da influência do fator nível de escolaridade no uso da regra de concordância redundante. A autora questiona se a tendência ao uso dessa regra seria um efeito direto de educação formal do falante ou um efeito indireto das oportunidades de ascensão social proporcionadas por um nível mais alto de escolaridade e as redes sociais estabelecidas pelos falantes. Tal argumentação fundamenta-se nos resultados de seu estudo conduzido com falantes de São Paulo, visto que na comparação sistemática estabelecida entre os fatores nível de escolaridade e classe social, o último se mostrou mais relevante que o primeiro.

Como vimos até aqui, o papel da saliência fônica tem despertado um grande interesse dentro das pesquisas relativas à concordância nominal variável. No entanto, como também foi salientado, não existe um consenso na literatura a respeito da real relevância e dos efeitos de tal variável. É nesse contexto que decidimos investigar experimentalmente o papel desempenhado por essa variável - no que tange aos processos morfofonológicos de formação de plural -, bem como uma possível interação entre esse fator e o fator social, nível de escolaridade na realização da concordância nominal de número no DP. Nosso objetivo principal é o de contribuir para uma melhor compreensão de tal fenômeno com o auxílio do arcabouço teórico e metodológico fornecido pela psicolinguística experimental.

Antes de passarmos ao relato experimental, apresentamos de forma sucinta a caracterização formal da concordância no âmbito do DP assumida no desenvolvimento de nossa pesquisa empírica. Destacamos ainda algumas análises que buscam dar conta da variação com relação à marcação morfofonológica de plural atestada na língua.

\section{Concordância nominal no PB: breve caracterização formal}

Magalhães (2004), em pesquisa sobre o PB, defende que seja utilizado o mesmo mecanismo de concordância Agree para o nível sentencial e para as relações no interior do DP. Para a autora, a concordância entre os elementos do DP aconteceria em duas etapas: primeiramente, dá-se a valoração dos traços- $\phi$ (gênero, número e pessoa) dos elementos concordantes e, em seguida, todo o DP tem seu traço de Caso valorado por uma sonda. Ademais, Magalhães não assume uma projeção Num, nem a existência de uma categoria funcional 
independente. A estrutura de DP defendida por Magalhães (2004:159) pode ser vista em (4) abaixo.

(4) Estrutura interna do DP proposta por Magalhães (2004)

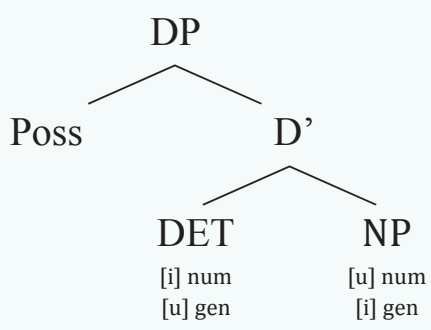

No que tange à discussão a respeito do locus da interpretabilidade do traço de número no DP, Magalhães (2004) baseia-se na estrutura de DP proposta por Abney (1987) para defender a ideia de que D teria traço de número [+interpretável] e traço de gênero [-interpretável], ao passo que $\mathrm{N}$ apresentaria traço de número [-interpretável] e traço de gênero e pessoa [+interpretável]. A escolha da autora justifica-se em virtude da possibilidade, no PB, de omissão de marca explícita de plural nos demais elementos do DP. Tal hipótese é compartilhada também por Costa e Figueiredo Silva (2006). Vale salientar que Magalhães (2004) defende que, mesmo no inglês em que a marcação de número se dá de maneira diferente do português - sendo realizada exclusivamente em $\mathrm{N}$ e estando ausente, portanto, em $\mathrm{D}$ e no modificador - $\mathrm{o}$ traço de número seria interpretável em D. A justificativa para tal argumentação recai nas evidências relativas ao funcionamento dos demonstrativos these e those que ocorrem na mesma posição que os determinantes (5) e apresentam marca explícita de número como ilustrado no exemplo (6).

(5) The boy/ The boys.

(6) These/ Those boys.

Essa caracterização se mostra compatível com a descrição do PB apresentada anteriormente em virtude da regra de concordância não redundante nessa língua, de acordo com a qual a marca morfológica de número é mantida somente na categoria em que tal traço é interpretável: (i) o sujeito da sentença na concordância verbal (lembrando que este pode corresponder ao argumento externo do verbo, nos verbos transitivos e inergativos, ou ao argumento interno, no caso dos inacusativos); e (ii) D ou Poss na concordância no âmbito nominal.

Em contrapartida, Ferrari-Neto (2008) argumenta que, no PB, a realização da regra não redundante no $\mathrm{PB}$ não está condicionada ao locus da interpretabilidade do traço de número, nem à interpretabilidade do traço em si. Segundo o autor, o fenômeno da concordância variável de número no PB é favorecido por outros fatores. Para defender essa ideia, Ferrari-Neto lança mão de algumas propostas disponíveis na literatura. A primeira remete ao trabalho 
de Costa e Figueiredo Silva (2006), no qual é defendido que a ocorrência de concordância não redundante no PB estaria relacionada ao fato de o morfema associado com a pluralidade ser do tipo singleton - isto é, tal morfema se adjunge exclusivamente ao elemento que recebe a interpretação semântica relativa à informação de número. Em relação ao mesmo fenômeno no português europeu, os autores consideram que o morfema associado à pluralidade em tal língua seja do tipo dissociado, ou seja, seria inserido após spell-out pelo componente morfológico, e sua afixação ocorreria independentemente de ter havido movimento sintático.

Ainda considerando a proposta de Costa e Figueiredo (2006), Magalhães e Silva (2014) apresentam argumentos em favor da existência de uma competição entre gramáticas no $\mathrm{PB}$, tanto no contexto urbano quanto no rural, no âmbito da concordância nominal e verbal. Nesse sentido, as autoras sugerem que a proposta de Costa e Figueiredo Silva (2006) de que o morfema de número no PB é do tipo singleton não se sustenta, visto que tal análise não leva em conta a variação efetiva existente no $\mathrm{PB}$.

Uma segunda proposta de análise que pretende dar conta da variação dos padrões de concordância no DP no PB estaria relacionada ao enfraquecimento do paradigma morfológico da flexão nominal de número no curso da evolução da língua, desde o latim até o estágio atual do PB observado em estudos como o de Nunes (1963 apud Ferrari-Neto 2008).

No presente artigo, assumimos a proposta de Magalhães (2004) no que tange: (i) ao mecanismo de concordância no DP (a saber, a operação Agree) por compartilharmos com ela a ideia de que a existência de mecanismos diferentes seria antieconômico para um sistema de base minimalista; e (ii) ao locus da interpretabilidade do traço de número em $\mathrm{D}$, visto que a marca explícita de plural pode ser expressa somente em $\mathrm{D}$ e, portanto, podendo ser eliminada dos demais itens do DP, sem acarretar agramaticalidade.

\section{Processamento da concordância nominal variável: o papel da saliência}

Os experimentos que reportamos a seguir tiveram como objetivo principal investigar o processamento da concordância nominal variável no $\mathrm{PB}$ em função da saliência fônica por falantes adultos. Para tal, foram elaboradas duas tarefas experimentais baseadas na técnica de produção eliciada por repetição. A escolha dessa técnica justifica-se em virtude de estarmos analisando um fenômeno muito frequente na modalidade oral, mas com um menor índice de ocorrência na escrita e, certamente, um fenômeno ainda socialmente estigmatizado. As tarefas experimentais foram desenvolvidas com o intuito fundamental de permitir registrar o tempo de reação (TR) dos participantes diante dos estímulos-alvo. Nesse sentido, os testes conduzidos visam a avaliar a percepção dos falantes 
no que diz respeito ao contraste entre regras redundante e não redundante de marcação morfofonológica de número no interior do DP. Além disso, julgamos que, ao introduzir como variável dependente a repetição de sentenças contendo ambas as regras de marcação da concordância (redundante e não redundante), poderíamos avaliar - embora de forma bastante indireta - se os falantes tratam de forma diferenciada essas estruturas no que tange à sua produção.

Assumimos como pressuposto de base a efetiva atuação do princípio da saliência fônica, de acordo com o qual formas mais salientes tendem a preservar a marca morfológica redundante de plural. A postulação desse princípio justificase a partir de abordagens descritivas ancoradas em diversas análises de corpora (Braga 1977, Guy 1981, Scherre 1978, 1988, 1991, 1994), mas ressaltamos que não tem sido investigado até então o processamento psicolinguístico de tais formas. Na presente pesquisa, especificamente, levantamos como hipótese a ideia de que, quando considerada a dimensão cognitiva do fenômeno de variação pesquisado, itens salientes e não salientes devem ser percebidos e produzidos de forma diferenciada pelos falantes.

Ambos os experimentos conduzidos empregaram a técnica de produção eliciada por repetição. Vale lembrar que estudos relativos ao processamento da variação linguística são - de modo geral - muito escassos e, especificamente, no caso do PB não há praticamente nenhum estudo que possa ser tomado como referência (cf.: Marcilese et al. 2015, Azalim 2016, Henrique 2016). Nesse sentido, nossa pesquisa é pioneira e, ao mesmo tempo, tem um caráter exploratório, tanto na abordagem do fenômeno quanto nos próprios recursos metodológicos a serem empregados na investigação.

Experimentos de produção eliciada e, pontualmente, de produção via repetição, têm sido frequentemente utilizados na investigação da fala de crianças e adultos com algum tipo de comprometimento linguístico, principalmente em quadros de afasia. No que tange à pesquisa com adultos sem alterações, tarefas de produção eliciada também são comuns, embora experimentos de repetição sejam mais usuais no caso de tarefas de sombreamento, nas quais o participante deve repetir a frase enquanto a ouve. No caso específico dos experimentos aqui reportados, utilizou-se a produção eliciada por repetição de sentenças por entendermos que a mesma possibilitaria a avaliação inicial do comportamento linguístico de falantes adultos frente às duas regras gerais de concordância tanto por meio da aferição dos tempos de reação, quanto através das análises das repetições não alvo. Durante a tarefa concebida, os participantes são apresentados a estímulos linguísticos contendo a estrutura alvo - no caso, um DP formado por D (no plural) + nome [+/- saliente] (no singular ou no plural), seguida por um sinal sonoro (bip). Ao ouvir o sinal, o participante deveria repetir imediatamente o estímulo ouvido, da maneira mais natural possível.

Thornton (1996) argumenta que a técnica de produção eliciada apresenta diversas vantagens para a pesquisa. Segundo a autora, os dados de produção são 
capazes de revelar a gramática do participante sem a necessidade de se fazerem inferências com base em respostas do tipo "sim" e "não". Sendo assim, os dados de produção eliciada, por exemplo, poderiam ser interpretados como um reflexo mais direto da gramática da criança ou do adulto. Ademais, a produção eliciada por imitação/repetição utiliza-se do mesmo raciocínio que subjaz à produção de fala espontânea. Afinal, ao reproduzir um enunciado linguístico, o indivíduo não age de forma mecânica, como se fosse um simples "gravador", ou mesmo um papagaio. Ao contrário, numa visão psicolinguística defende-se que, em termos processuais, as etapas envolvidas na fala espontânea seriam as mesmas envolvidas na produção por repetição/imitação. Nesse sentido, em ambas as situações, haveria a necessidade de planejamento da fala, acesso lexical, formulação sintática e codificação morfofonológica do enunciado, etapas prévias à efetiva articulação.

\subsection{Experimento 1: concordância nominal e saliência fônica em nomes reais do $P B$}

Os objetivos específicos do Experimento 1 foram:

(i) Analisar a produção de sentenças com concordância redundante vs. concordância não redundante no âmbito do DP por falantes adultos do $\mathrm{PB}$ e verificar se os participantes repetiriam as sentenças tal como foram ouvidas (= repetições-alvo) ou se as repetiriam corrigindo eventuais incongruências;

(ii) Verificar se o fator saliência fônica se mostra relevante para prever o número de repetições-alvo e o tempo de reação frente aos estímulos experimentais;

(iii) Avaliar experimentalmente em que medida o nível de escolaridade constitui um fator relevante na realização das diferentes regras de concordância variável, como tem sido apontado por pesquisas de cunho sociolinguístico.

\subsubsection{Método}

Foram consideradas as seguintes variáveis independentes: saliência (itens $+/$ - salientes), concordância (redundante e não redundante) e nivel de escolaridade (níveis superior e fundamental), sendo os dois primeiros fatores within subjects (medidas repetidas) e o terceiro between subjects, i.e, um fator grupal. No que tange à variável saliência, contrastamos nomes tidos como [+salientes], por exemplo, (dever/deveres) vs. nomes [-salientes], tais como, (maiô/maiôs). Vale ressaltar que a escolha de tais itens como [+/-salientes] toma como base a escala hierárquica de saliência proposta por Scherre (1988). No 
nível tido como [+saliente] selecionamos itens terminados ortograficamente em -R ou -L. No extremo oposto da hierarquia, escolhemos os itens classificados como [-salientes]: nomes cuja forma plural se dá apenas pela inserção de -S. As variáveis dependentes consideradas foram: o número de repetições-alvo e o tempo de reação para a repetição, que, neste caso, consistiu no intervalo entre o fim do estímulo auditivo e o onset da repetição. A frequência de ocorrências de formas singulares e plurais dos nomes selecionados para a construção dos estímulos experimentais também foi levada em consideração. A seguir, apresentamos exemplos das quatro condições experimentais (lembrando que nível de escolaridade foi tomado como fator grupal). $\mathrm{O}$ segmento relevante para nossa análise foi o DP que encerrava as sentenças experimentais (DP-alvo, destacado em negrito nos exemplos), i.e. o último elemento que o participante ouvia antes de iniciar a repetição propriamente dita:

- Condição A: nome [+saliente] + concordância redundante (plural)

Antes de pendurar as roupas, limpe os varais.

- Condição B: nome [+saliente] + concordância não redundante (singular)

Antes de pendurar as roupas, limpe os varal.

- Condição C: nome [-saliente] + concordância redundante (plural) Ele adora tirar onda com os bonés.

- Condição D: nome [-saliente] + concordância não redundante (singular)

Ele adora tirar onda com os boné.

Foram levantadas as seguintes previsões experimentais:

(a) No que tange ao TR, caso o participante registre algum estranhamento na escuta do DP-alvo, espera-se que o início da repetição seja retardado. Assim, condições eventualmente percebidas como "anômalas" devem registrar TRs maiores;

(b) Se saliência é um fator que favorece a marcação redundante de número, as condições $\mathrm{A}, \mathrm{C}$ e $\mathrm{D}$ não devem apresentar diferenças significativas entre si nos TRs e no número de repetições-alvo. Já a condição B deveria registrar os maiores TRs;

(c) Caso a saliência não seja fundamental para a ocorrência da concordância redundante, espera-se um número equivalente de repetições-alvo nas condições redundantes (A e C) quando comparadas com as condições não redundantes (B e D);

(d) No que tange ao fator nivel de escolaridade, de acordo com o observado nos dados naturalistas, espera-se que a correlação direta 
entre grau de saliência e padrão morfológico de número tenha um papel relevante a depender do nível de escolaridade do participante.

Vale salientar que um eventual (aparente) estranhamento registrado em função do número de repetições-alvo na nossa tarefa experimental não constitui, necessariamente, um indicador da relevância das variáveis independentes manipuladas (quais sejam, saliencia e nivel de escolaridade), mas pode decorrer de um efeito de "normatividade", principalmente no caso de falantes com nível de escolaridade superior ${ }^{5}$. Assim, mesmo um falante que na sua produção espontânea apresente alternância na realização morfofonológica da marcação de plural, diante de uma situação experimental, pode reforçar o monitoramento da sua fala e tender a adequar sua produção à norma padrão. Como veremos mais adiante, tal efeito de normatividade parece efetivamente ter ocorrido no nosso primeiro experimento e foi um dos fatos que nos levaram à elaboração do Experimento 2.

\section{Participantes}

Participaram 36 voluntários divididos em dois grupos em função da variável nível de escolaridade: ensino superior completo ou em andamento (Grupo 1) e fundamental II completo (Grupo 2). O primeiro grupo foi composto por 24 estudantes universitários (17 mulheres e 7 homens), com idades entre 17 e 39 anos (idade média: 21 anos). No segundo grupo participaram 12 estudantes (2 mulheres e 10 homens), com idades entre 18 e 30 anos (média de idade: 23 anos), cursando a Educação de Jovens e Adultos (EJA) de uma escola da rede estadual de ensino em Juiz de Fora.

\section{Materiais}

Para a elaboração e aplicação do experimento, foi preparada uma apresentação a partir do programa Power Point, que era projetada num computador portátil. Foram utilizados ainda alto-falantes, um gravador digital de alta resolução, fones de ouvido e um adaptador para permitir a saída de som tanto para os alto-falantes quanto para o fone de ouvido (de modo que o gravador captasse tanto o estímulo linguístico apresentado para o participante, quando a produção do falante). Os estímulos experimentais foram de natureza exclusivamente acústica, os quais foram gravados no Laboratório de Atividades Experimentais do NEALP, e posteriormente editados por meio do software Praat $^{6}$. Tais estímulos consistiam de um conjunto de 36 sentenças (12

5. Agradecemos os comentários de um dos avaliadores deste artigo que reforçou a importância dessa questão.

6. Boersma e David Weenink (2008), versão 6.0.29, disponível em http://www.fon.hum.uva.nl/praat/. 
experimentais - sendo 3 por condição - e 24 distratoras), seguindo a estrutura de quadrado latino. A ordem de apresentação dos estímulos foi semi-aleatorizada manualmente.

Vale lembrar que, como já mencionado anteriormente, no estudo de Scherre (1988), o fator da saliência fônica é caracterizado sob três dimensões, a saber: processos morfofonológicos de formação do plural, tonicidade da sílaba dos itens lexicais singulares e número de sílabas dos itens lexicais singulares. Entretanto, em nossa pesquisa optamos por analisar tal variável exclusivamente sob a dimensão dos processos morfofonológicos de formação do plural dos itens selecionados, objetivando manter um controle maior das variáveis independentes. Por esse motivo, a escolha dos itens nominais para compor as sentenças experimentais foi realizada em função de uma caracterização da saliência fônica sob o viés dos processos morfofonológicos de formação de plural. Isto é, outras dimensões não foram o foco deste estudo. Decidimos por priorizar (dentre os níveis da escala de Scherre 1988) três formas específicas de saliência, a saber: itens nominais cuja forma singular termina em -R ou -L foram tomados nesta pesquisa como [+salientes], e itens regulares foram avaliados como [-salientes]. A escolha pelas formas em $-\mathrm{R}$ e -L justifica-se por demonstrarem uma oposição bem evidente no material fônico quando comparadas aos itens regulares no que tange aos processos morfofonológicos de formação do plural delimitados no referido estudo (Scherre 1988:30). Cabe destacar que, como foi anteriormente mencionado, esses dois tipos de itens (-R e $-\mathrm{L}$ ) apresentam diferenças entre si no que diz respeito à tonicidade - com a possibilidade de alternância de padrão acentual no contraste entre a forma singular e plural de um mesmo item - e, ainda, com a possibilidade de variação no número total de sílabas na oposição entre forma singular e plural. No entanto, de acordo com a escala de saliência adotada para a presente pesquisa, ambos os tipos de item são considerados como mais salientes quando comparados com os plurais regulares. Os demais graus de saliência propostos por Scherre (1988) não foram considerados no presente experimento (cf.: Azalim (2016) para uma justificativa detalhada das decisões metodológicas nesse sentido).

Todos os nomes selecionados para compor os itens experimentais foram dissílabos e oxítonos. Escolhemos esse padrão silábico por ser um dos dois padrões mais comuns (= com maior número de itens) na língua, junto com os dissílabos paroxítonos (Collischonn 1996). Com isso, para a construção dos estímulos experimentais, escolhemos seis itens nominais [+salientes], sendo três com terminação em -R e três em -L. Dentre esses nomes, três apresentam uma frequência maior na forma singular ${ }^{7}$ (pomar, quartel e varal) e três na forma plural (dever, lençol e talher). Em contraste com as formas [+salientes], foram selecionados também seis itens nominais [-salientes]. Para evitarmos um 
viés de número nas repetições-alvo (maior frequência de uso das formas no singular ou no plural), seguimos o mesmo critério que usamos para as formas [+salientes], ou seja, selecionamos três itens com maior frequência no singular (caju, robô e trenó) e três no plural (balé, boné e maiô).

Todas as sentenças foram gravadas e editadas por meio do software Praat. No final de cada frase, foi adicionada uma pequena pausa $(100 \mathrm{~ms})$ seguida de um curto sinal sonoro (bip) com duração aproximada de 130 milésimos de segundo, que indicava para o participante o momento de iniciar a repetição.

\section{Procedimento}

O experimento foi aplicado a todos os participantes individualmente. Para a realização da tarefa, eles foram, inicialmente, instruídos oralmente pelos pesquisadores a usarem o fone de ouvido. Em seguida, receberam instruções exibidas na tela do computador, segundo as quais eles ouviriam algumas sentenças que, por sua vez, seriam seguidas de um sinal sonoro. Após ouvir tal sinal, os participantes deveriam repetir a sentença da maneira mais natural possível. Foi enfatizado que eles deveriam repetir a sentença ouvida, empregando a velocidade e prosódia que achassem adequadas. Para os participantes, o objetivo da tarefa era a conformação de um banco de áudios que seria posteriormente empregado em experimentos (para o qual eram necessárias várias amostras da mesma frase produzida por diversos falantes). Com essa instrução, era explicitado que toda a produção seria gravada. A apresentação dos estímulos ocorria de forma automática, ou seja, após ouvir a sentença e o bip, o participante dispunha de em torno de seis segundos para repetir a sentença ouvida. A seguir, apresentamos um esquema que ilustra o procedimento experimental.

Figura 1 - Esquema do procedimento experimental

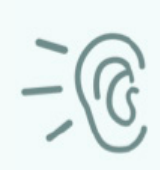

frase

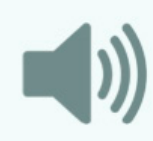

bip

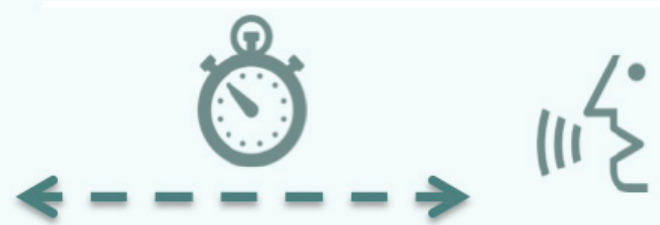

tempo de reação repetição

Para fins de análise, foram gravados o estímulo acústico emitido pelo altofalante, bem como as repetições produzidas pelos participantes. Na aferição dos resultados, o TR - isto é, o intervalo de tempo entre o sinal sonoro e o onset das repetições - foi mensurado por meio do software Praat. 


\subsubsection{Resultados e discussão}

Inicialmente, foi conduzida uma análise da variância com design $2 \times 2 \times 2$ (Grupo*Saliência*Concordância), que não revelou efeito principal da variável grupo e nem interações relevantes entre essa variável e as restantes. Por esse motivo, optamos por analisar cada um dos grupos de forma independente. Foram conduzidas análises em função das duas variáveis dependentes delimitadas: tempo de reação e número de repetições-alvo. Os dados relativos aos TR (mensurados em milésimos de segundo) foram submetidos a uma análise da variância (design fatorial 2x2 - Saliência*Concordância). No Grupo 1 (universitários), observou-se um efeito principal de concordância $(\mathrm{F}(1,23)=$ $10,3 p=.003$ ), com tempos médios significativamente ${ }^{8}$ maiores nas condições de concordância não redundante. Um efeito semelhante foi registrado para o Grupo 2 (EJA) $(\mathrm{F}(1,11)=13,8 p=.003)$. O Gráfico 1, a seguir, apresenta os resultados relativos a ambos os grupos em função do efeito principal de concordância.

Gráfico 1 - Médias de TR dos Grupos 1 e 2 em função de concordância

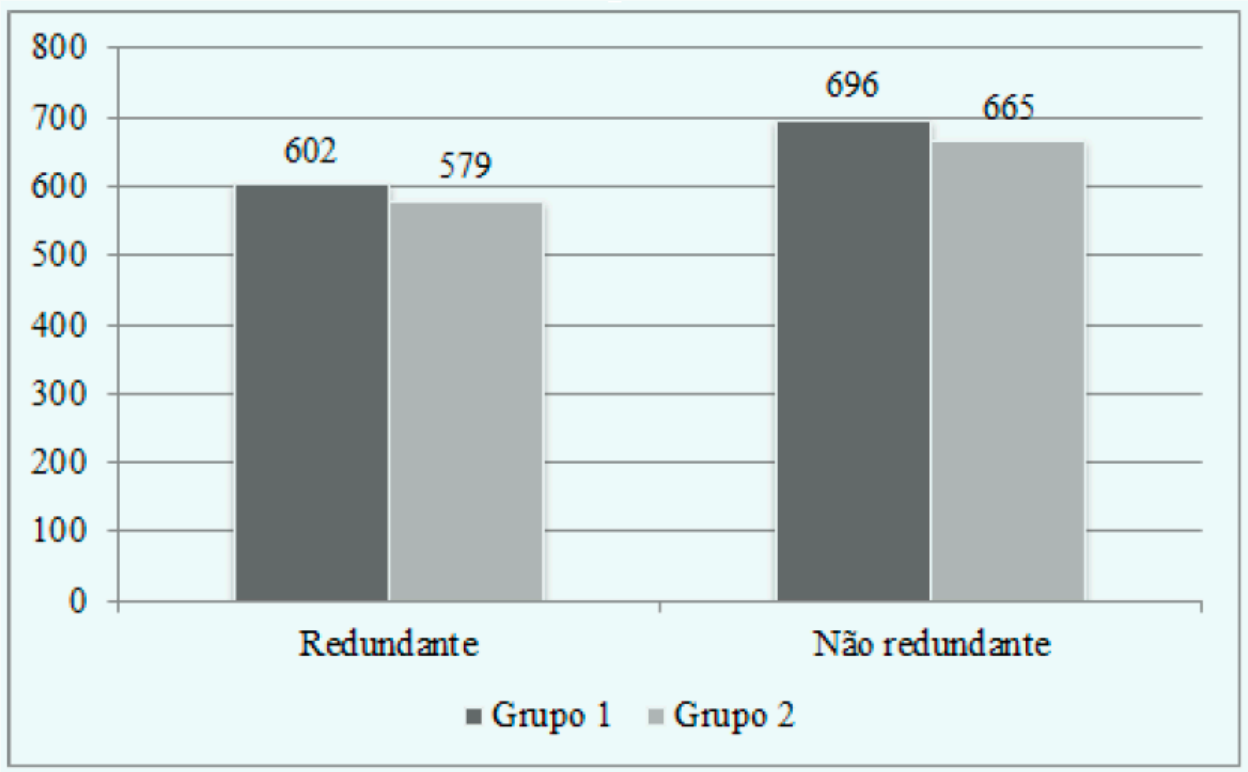

Não houve efeito principal de saliência nem efeito significativo da interação entre as variáveis analisadas para o Grupo 1. Diferentemente, no Grupo 2 registrou-se um efeito principal de saliência $(\mathrm{F}(1,11)=5,02 p=.046)$, com médias de tempos de resposta significativamente maiores na condição não saliente. Não houve, novamente, efeito de interação entre as variáveis. $\mathrm{O}$ Gráfico 2 exibe os resultados de ambos os grupos em função de saliência do nome. 
Gráfico 2 - Médias TR nos Grupos 1 e 2 em função de saliência

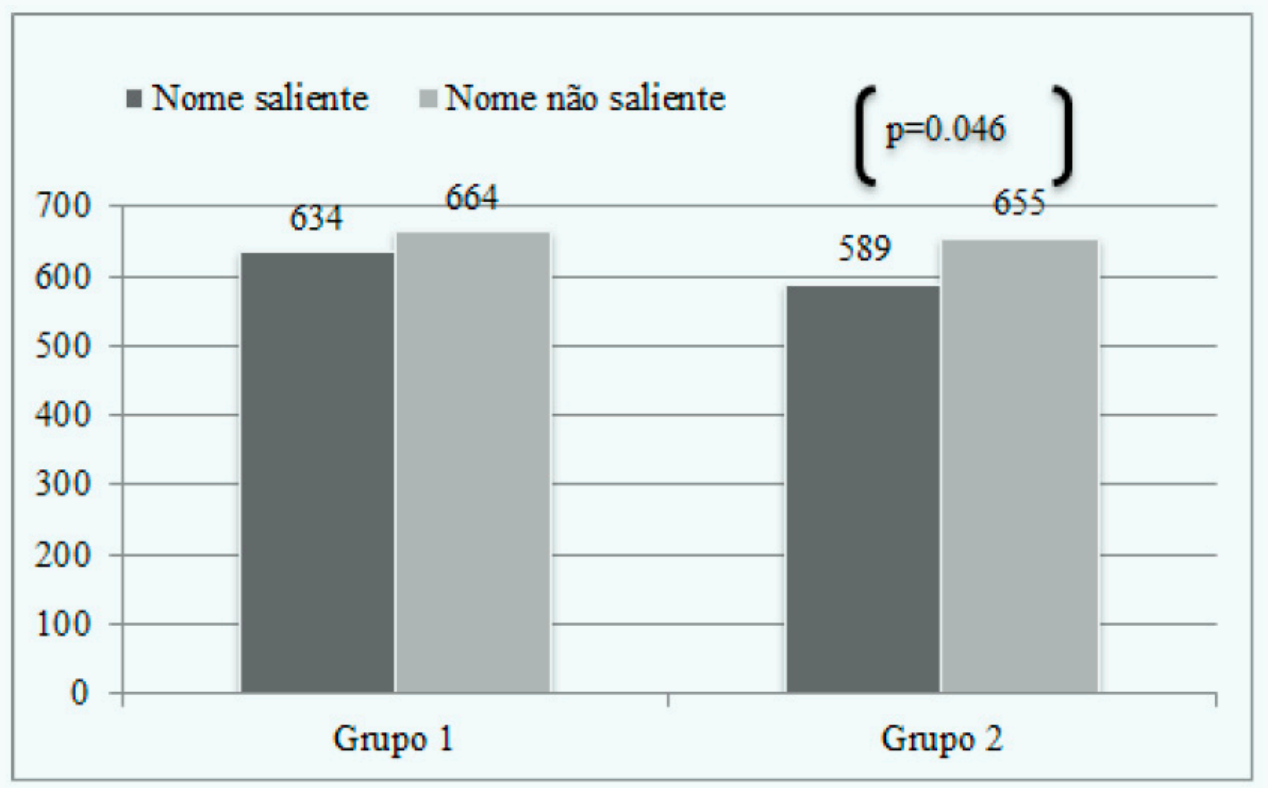

Ainda no que diz respeito à variável dependente tempo de reação, foram realizadas comparações entre pares de condições por meio de teste $t$ (pareado, bicaudal). Reportamos aqui apenas resultados que consideramos relevantes para a discussão que trazemos a seguir. Em ambos os grupos, foi registrada uma diferença estatisticamente significativa ${ }^{9}$ nos TRs quando comparadas as condições nome não saliente + concordância redundante e nome não saliente + concordância não redundante (Ex. os bonés versus os boné). Nesse caso, a condição não redundante registrou TRs maiores (Grupo $1(\mathrm{t}(23)=3,06 p=.005)$, Grupo $2(\mathrm{t}(11)=4.85 p=.0005)$. Esse efeito não foi registrado para os nomes mais salientes em nenhum dos dois grupos. Retomaremos esses resultados mais à frente, ao reportar os resultados do segundo experimento. O Gráfico 3 apresenta as médias de TR por grupo em cada uma das quatro condições experimentais. 
Gráfico 3 - Médias de TR por condição experimental nos Grupos 1 e 2

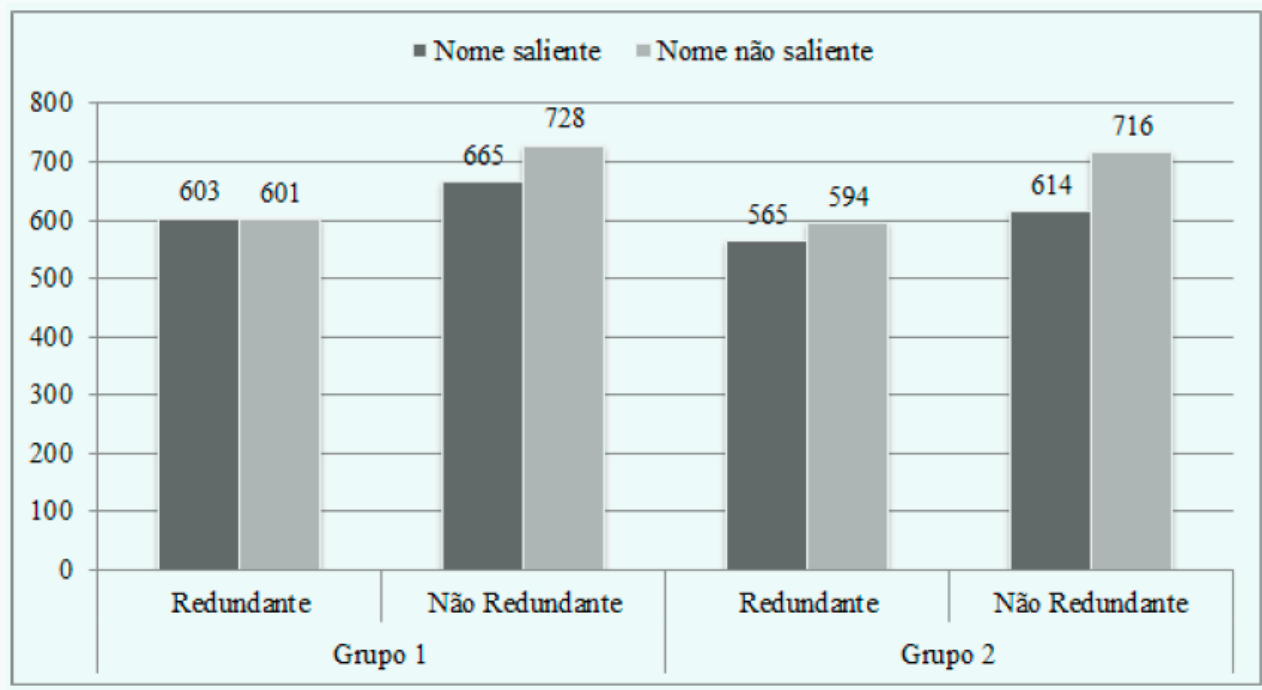

No que tange à segunda variável dependente (média de repetições-alvo), foi aplicado o teste de Wilcoxon para análises pareadas e em ambos os grupos foi registrada uma diferença estatisticamente significativa entre as condições redundante e não redundante, com médias de repetição-alvo maiores na condição redundante (Grupo $1\left(\mathrm{Z}=4.046^{\mathrm{a}} p=.000\right)$, Grupo $2\left(\mathrm{Z}=3.093^{\mathrm{a}} p=.002\right)$.

Gráfico 4 - Médias de repetições-alvo nos Grupos 1 e 2 em função de concordância (Max Score $=6$ )

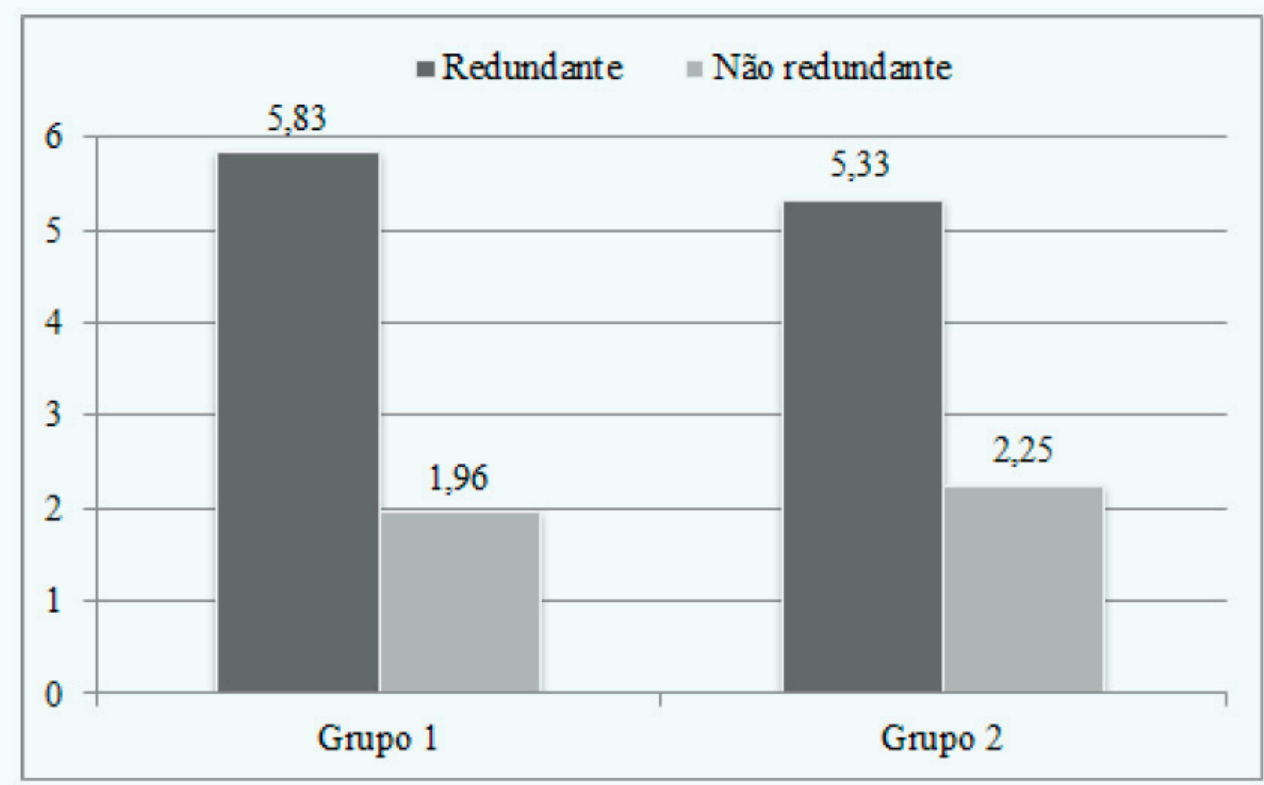

Quando considerado o número de repetições, não foi registrado efeito de saliência para nenhum dos grupos ( $\mathrm{G} 1\left(\mathrm{Z}=-.749^{\mathrm{a}} p=.454\right)$, com médias de 3.83 para os itens salientes e de 3.96 para os não salientes; $\mathrm{G} 2\left(\mathrm{Z}=-.551^{\mathrm{a}} p=.582\right)$ 
com médias de 3.67 e 3.92, para cada tipo de item). No Gráfico 5, apresentamos as médias de repetição-alvo por condição em cada grupo.

Gráfico 5 - Médias de repetições-alvo por condição experimental nos Grupos 1 e 2 (Max Score $=3)$

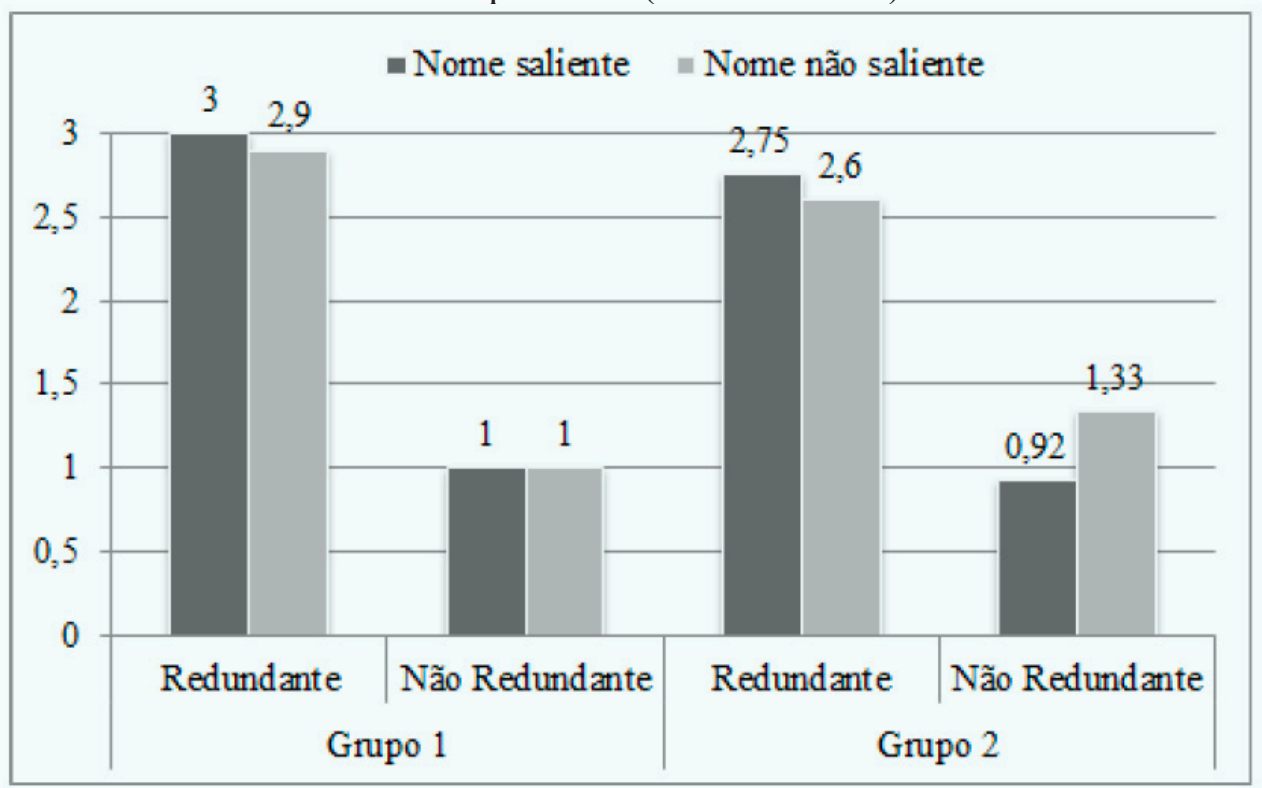

As médias de repetições-alvo foram significativamente maiores nas condições com concordância redundante, independentemente da saliência dos itens. Nesse sentido, os dados de produção parecem indicar que o paralelismo formal-estabelecido entre D e o núcleo do sintagma nominal, independentemente de o nome pertencer ao grupo classificado neste estudo como [-saliente] como em os bonés, ou [+saliente] como os quarteis, pode ter exercido influência maior no processamento da concordância de número no âmbito do DP do que o fator da saliência fônica.

Os resultados de ambos os grupos tomados em conjunto vão na mesma direção do reportado em algumas pesquisas desenvolvidas no contexto da Sociolinguística (Nicolau 1984, 1995, Campos 2015), que sugerem que a saliência não teria um papel relevante na realização da concordância redundante de número - contrariando os achados da grande maioria dos trabalhos que investigam o papel de tal fator. Nicolau (1984), tomando como base a concordância no nível sentencial, conclui que:

“[...] não há qualquer evidência de relação entre a ausência de concordância verbal e o grau de saliência fônica que diferencia as formas verbais de singular e as de plural. O fato de, nos verbos "regulares" (fala/falam, come/comem, faz/fazem etc.), a ausência de concordância ser mais frequente pode ser explicada pela ocorrência de interação entre um processo morfossintático variável sincrônico e alguns processos fonológicos variáveis 
que atingiram esses verbos, ainda no português arcaico." (Nicolau 1984:176)

Analisando especificamente o desempenho dos participantes do Grupo 2 (EJA), os resultados em relação à saliência dos itens demandam uma explicação adicional. Contrariando as previsões iniciais, os itens [+salientes] representados aqui por itens terminados em -R e -L no singular - registraram TRs menores do que itens [-salientes] - aqui representados pelos denominados plurais regulares. Faz-se necessário lembrar que, em princípio, nosso objetivo era analisar o fator saliência fônica exclusivamente a partir da dimensão dos processos morfofonológicos de formação de plural dos itens. Entretanto, nossos resultados parecem reforçar a hipótese formulada a partir de análise de corpora (Campos 2015), de que a tonicidade da sílaba na qual se marca explicitamente o plural pode ser mais relevante para a realização da regra de concordância redundante do que a quantidade de material fônico diferenciador na oposição singular/plural. Nos nossos estímulos experimentais, os itens terminados em -R (talher/talheres, dever/deveres, pomar/pomares) sofrem uma alteração no seu padrão de acentuação na forma plural, passando de oxítonos a paroxítonos. Já os itens terminados em -L (lençol/lençois, quartel/quarteis, varal/varais) preservam o acento na sílaba final, mas apresentam alternância no ditongo, passando do glide [w] para [j] acrescido de $-\mathrm{s}(\mathrm{V}[\mathrm{w}] \# \rightarrow \mathrm{V}[\mathrm{js}] \#)$. A despeito dessas diferenças, o comportamento dos participantes foi semelhante frente a itens em -R e em -L, não sendo verificada nenhuma diferença estatisticamente significativa entre esses itens.

Por outro lado, nos itens tidos como menos salientes o contraste entre marcação redundante e não redundante parece ter sido mais facilmente percebido pelos participantes. Vale lembrar que, em algumas variantes, podemos ter

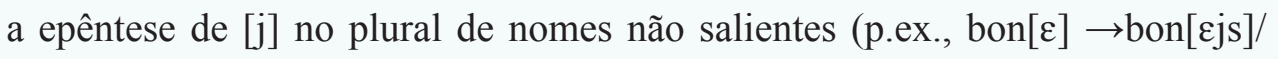
[عj]]), se assemelhando, em termos fonéticos, à forma plural de nomes salientes terminados em $[w]$ (p.ex., an[cw] $\rightarrow$ an $[\varepsilon j s] /\left[\varepsilon j \int\right]$. É importante frisar que a saliência fônica é uma propriedade definida pelo contraste de material fônico quando comparadas as formas singular e plural de um mesmo item. Nesse sentido, embora as formas plurais possam se assemelhar, o que deve ser considerado na avaliação da saliência é o par singular-plural de cada item. Desse modo, o contraste em termos de saliência fônica entre pares como bonébonés e anel-anéis permanece.

Quando consideramos o número de respostas-alvo, diferentemente do que tem sido observado na grande maioria dos estudos de cunho sociolinguístico (Braga 1977, Scherre 1978, 1988, 1991, Lopes; Scherre 2014), de acordo com os quais itens [+salientes] favorecem a marca de plural e itens [-salientes] a desfavorecem, o Experimento 1 revelou uma tendência dos participantes pelo uso da marca explícita de plural na grande maioria das situações registradas, independentemente do processo morfofonológico de formação dos itens em 
questão. Isto é, mesmo quando o estímulo-alvo era não saliente (Ex. os boné), os participantes de ambos os grupos apresentaram uma tendência a "corrigir" a frase, transformando a concordância não redundante em redundante (Ex. os boné produzido como os bonés ou como o boné).

Em função desse tipo de comportamento, desenvolvemos um segundo experimento no qual os nomes reais do PB foram substituídos por pseudonomes. Com essa alteração, buscamos inibir um possível efeito do conhecimento prévio dos itens, incluindo aspectos tais como a frequência de uso dos nomes nas formas singulares e plurais e neutralizar um possível efeito de "normatividade". O Experimento 2 foi conduzido apenas com estudantes universitários e visou, portanto, a isolar a influência da dimensão morfofonológica da saliência de outros aspectos relevantes que podem ter afetado a resolução da tarefa no Experimento 1.

\subsection{Experimento 2: concordância nominal e saliência em pseu- do-nomes ${ }^{10}$}

Os objetivos específicos do Experimento 2 foram:

(i) Verificar se a saliência fônica se mostra relevante para prever o número de repetições-alvo numa tarefa de produção eliciada e o tempo de reação frente aos estímulos experimentais;

(ii) Contrastar o desempenho dos participantes em tarefas de produção por repetição de frases com nomes reais do PB e com pseudo-nomes.

\subsubsection{Método}

As mesmas variáveis independentes do Experimento 1 foram mantidas, com exceção de nivel de escolaridade. Assim, foram consideradas: saliência (itens +/- salientes), concordância (redundante e não redundante). A classificação dos itens salientes e não salientes previamente estabelecida foi mantida ([+saliente] itens terminados ortograficamente em $-\mathrm{R}$ ou $-\mathrm{L}$, itens [-salientes] aqueles cuja forma plural se dá apenas pela inserção de -S). As variáveis dependentes consideradas foram as mesmas do Experimento 1: número de repetiçõesalvo e tempo de reação para a repetição. As condições experimentais foram semelhantes ao reportado para o primeiro experimento:

10. Agradecemos a Marina Maia e Polyana Layer, bolsistas de IC que integraram o projeto já em andamento e participaram das etapas de elaboração e aplicação do experimento. 
- Condição A: pseudo-nome [+saliente $]+$ concordância redundante (plural)

Antes de pendurar as roupas, limpe os mecais.

- Condição B: pseudo-nome [+saliente] + concordância não redundante (singular)

Antes de pendurar as roupas, limpe os mecal.

- Condição C: pseudo-nome [-saliente] + concordância redundante (plural)

Ele adora tirar onda com os nabés.

- Condição D: pseudo-nome [-saliente] + concordância não redundante (singular)

Ele adora tirar onda com os nabé.

As previsões originais foram mantidas, com o seguinte acréscimo: o uso de pseudo-nomes deve elevar o número de repetições-alvo, pelo fato de inibir pelo menos parcialmente - efeitos relativos ao conhecimento prévio dos itens.

\section{Participantes}

Participaram do experimento 25 voluntários, sendo todos estudantes universitários (19 mulheres e seis homens), com idades entre 18 e 28 anos (idade média: 21 anos).

\section{Materiais}

As frases construídas para o Experimento 1 foram tomadas como base para a elaboração dos estímulos do Experimento 2. Todos os nomes relevantes nos trials experimentais foram substituídos por pseudo-nomes seguindo o mesmo padrão de formação morfofonológica (mesmo número de sílabas e padrão acentual). Nas frases distratoras, também foram utilizadas pseudo-palavras, com o objetivo de dificultar a identificação do objetivo do teste para os participantes.

Em termos de equipamento, foi utilizado o mesmo aparato do Experimento 1. As novas frases foram gravadas seguindo os mesmos critérios empregados anteriormente e editadas utilizando o Praat, como já reportado.

\section{Procedimento}

O procedimento experimental foi idêntico ao do Experimento 1. A única diferença significativa foi o fato de que os participantes foram alertados sobre o fato de que as frases que seriam ouvidas continham palavras desconhecidas e que eles deviam procurar repetir as frases escutadas da forma mais natural possível. Não houve outras alterações relevantes no que diz respeito ao procedimento. 


\subsubsection{Resultados e discussão}

Novamente, os resultados foram analisados em função das duas variáveis dependentes previamente delimitadas. No que diz respeito ao TR, assim como no experimento anterior, foi obtido um efeito principal de concordância, com tempos significativamente maiores para os estímulos não redundantes $(\mathrm{F}(1,24)$ $=4.44 p=.04)$.

Gráfico 6 - Médias de TR em função de concordância

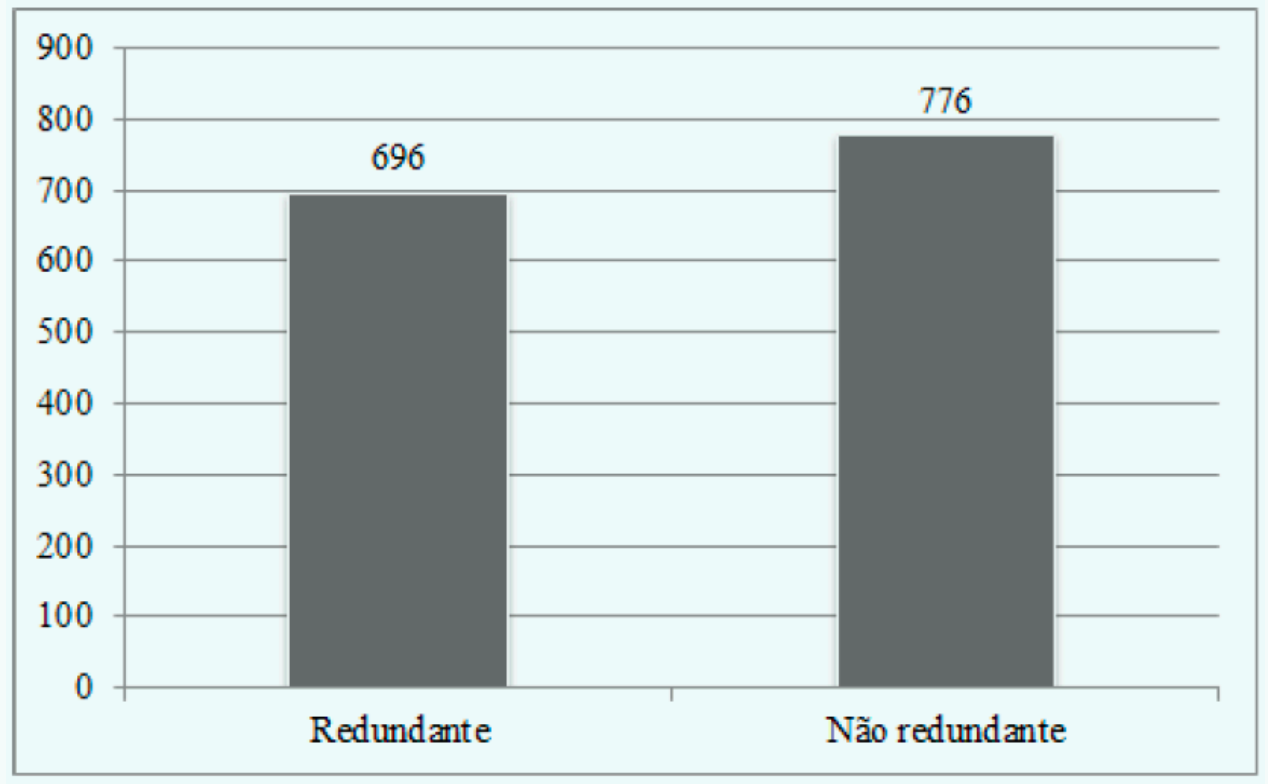

Não foi registrado efeito principal de saliência (médias: $750 \mathrm{~ms}$ para nomes salientes e $721 \mathrm{~ms}$ para nomes não salientes $(\mathrm{F}(1,24)=1.49 p=.2)$ ), nem efeito de interação $(\mathrm{F}(1,24)=0.448 p=.5)$. No entanto, na comparação entre pares, foi novamente obtida uma diferença entre as condições nomes não salientes redundantes e não redundantes $(\mathrm{t}(24)=2.07 p=.04)$, com médias de TR maiores para a concordância não redundante. Esse efeito foi semelhante ao observado previamente no Experimento 1. No Gráfico 7, comparamos os resultados desse contraste entre os três grupos avaliados (G1, G2 - Experimento 1 e os participantes do Experimento 2). Em todos os casos, a diferença se revelou estatisticamente significativa; o mesmo não foi observado para os nomes classificados inicialmente como [+salientes]. 
Gráfico 7 - Comparação das médias de TR das condições Nomes não saliente concordância redundante e não redundante para pseudo-nomes e nomes reais do PB

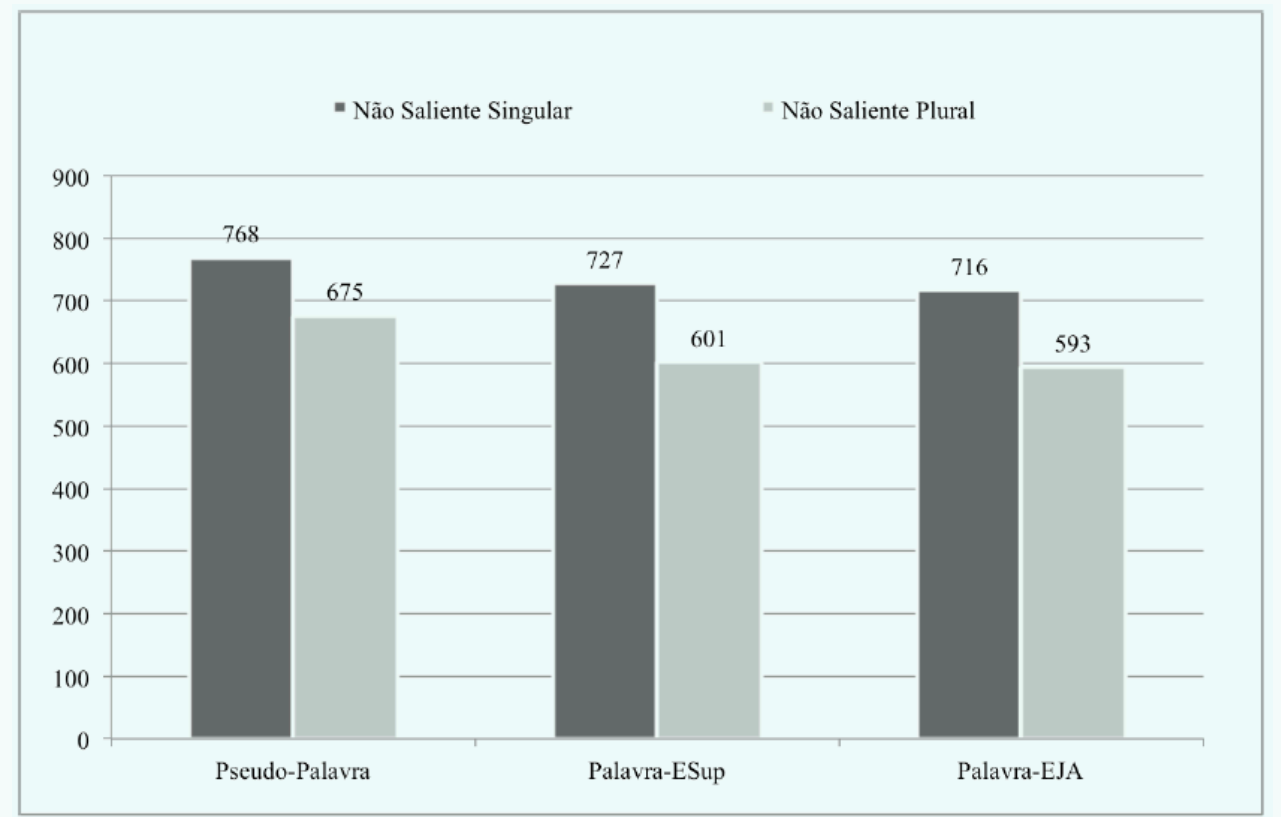

No que diz respeito à segunda variável dependente, o número de repetiçõesalvo registrou um aumento expressivo quando comparado com os resultados do Experimento 1. O teste de Friedman revelou diferença significativa entre as condições $\left(\chi^{2}(3,25)=8.02 p=.04\right)$; no entanto, no teste post hoc (Wilcoxon), não foram registradas diferenças na comparação entre pares. A diferença registrada no teste de Friedman possivelmente deriva do fato de termos registrado um número maior de repetições-alvo nas condições redundantes. A média de repetição-alvo para os estímulos redundantes foi de 5.92, enquanto que para os estímulos não redundantes foi registrada uma média de 5.32 (Max Score $=6$ ). Nesse sentido, os resultados seguem a tendência observada no Experimento 1, embora com um incremento geral do número de respostas esperadas.

Ainda com relação ao número de repetições, a variável saliência não foi relevante em nenhuma das análises conduzidas.

Os resultados do Experimento 2 sugerem que o uso de pseudo-palavras se mostrou um recurso bastante pertinente, permitindo neutralizar possíveis efeitos do conhecimento prévio dos itens lexicais e - até mesmo - do julgamento dos estímulos em função do prestígio social das variantes linguísticas investigadas, como indicado pelo aumento expressivo nas médias de repetição-alvo observado. Vale salientar também que, embora no número de repetições tenha havido uma clara diferença entre os dois experimentos, os TRs registrados foram na mesma direção em ambos os casos. Esse resultado reforça a confiabilidade dos 
nossos resultados iniciais no que diz respeito à percepção dos estímulos pelos participantes.

\section{Considerações finais}

Em conjunto, nossos resultados parecem contrariar a visão mais difundida na literatura com relação ao papel da saliência fônica na concordância nominal variável, mas se mostram compatíveis com o reportado por alguns estudos prévios (Nicolau 1984, 1995, Campos 2015). De acordo com Campos (2015), as formas pluralizáveis tendem a ser marcadas morfologicamente na forma redundante por falantes com nível superior completo, independentemente de serem mais ou menos salientes (Campos 2015). Em outros termos, no que tange à flexão de número dos elementos no interior do DP, compartilhamos com Campos (2015) a ideia de que a influência exercida pela saliência fônica sobre o comportamento linguístico dos falantes do PB com alto nível de escolaridade não parece ser significativa. Em contrapartida, os resultados do Grupo 2 (EJA) no nosso Experimento 1 sugerem que tal variável poderia ter alguma influência - em termos perceptuais - no comportamento linguístico de falantes com uma escolaridade menor. No entanto, nossos resultados sugerem que um eventual efeito estaria mais vinculado à tonicidade e não à saliência fônica em termos de quantidade de material fônico diferenciador das formas singulares e plurais. Essa interpretação se mostra compatível ainda com o contraste identificado - nos três grupos avaliados - no que diz respeito às formas redundantes e não redundantes quando associadas aos denominados "plurais regulares" (tipicamente tidos como não salientes fonologicamente). Os resultados obtidos em função da variável saliência parecem sugerir a necessidade de uma revisão da própria caracterização de saliência fônica quando a dimensão cognitiva e perceptual da variação é levada em consideração. Novas pesquisas que investiguem outras dimensões do fenômeno da saliência fônica, para além dos processos morfofonológicos de formação de plural, serão necessárias para que conclusões mais robustas possam ser aventadas.

Os TRs significativamente maiores registrados nas condições não redundantes são compatíveis ainda com o reportado em estudos prévios no que diz respeito a um aparente maior custo cognitivo associado ao processamento da concordância não redundante tanto nominal quanto verbal (Squires 2014 em estudo conduzido em inglês; para o PB cf.: Marcilese et al. 2015, Azalim 2016, Henrique 2016, Marcilese et al. 2017). O contraste entre marcação redundante e não redundante poderia, inicialmente, ser associado com um maior monitoramento dos falantes em situação de teste, em função de um "efeito de normatividade". Nesse sentido, falantes adultos em situação de avaliação podem buscar alinhar sua produção às variantes de prestígio - tal como parecem indicar os resultados de produção do Experimento 1 - e ficar mais atentos aos 
estímulos linguísticos, de modo geral. No entanto, diferenças nos TRs quando comparadas as variantes redundante e não redundante têm sido registradas até mesmo com crianças em etapa inicial de escolarização ( 6 anos de idade), o que reforça a tese de que os resultados registrados não são fruto apenas de uma consciência generalizada sobre o uso de variantes de maior prestígio na língua (cf.: Marcilese et al. em prep.).

As questões de pesquisa discutidas no presente artigo estão longe de serem esgotadas. Acreditamos, contudo que os resultados aqui reportados podem fornecer novos subsídios para o estudo do caráter variável da marcação morfofonológica de número no DP e sinalizam um caminho bastante produtivo para novas pesquisas - ainda inéditas no Brasil - a serem desenvolvidas no contexto do diálogo entre psicolinguística e sociolinguística, visando assim, a uma melhor compreensão da variação linguística em todas as suas dimensões.

Recebido em: 07/12/2016

Aprovado em: 07/07/2017

Emails:

Cristina Azalim gazalim@oi.com.br Mercedes Marcilese mmarcilese@gmail.com Cristina Name mcrisname@gmail.com Lilian Scher scherlilian@gmail.com Lydsson Gonçalves lydsson@hotmail.com

\section{Referências}

ABNEY, Steven. 1987. The English Noun Phrase in its Sentencial Aspect. PhD. Diss. MIT.

AZALIM, Cristina. 2016. Variação e processamento linguístico: um estudo experimental sobre a concordância nominal variável no PB. Dissertação (Mestrado em Linguística). UFJF, Juiz de Fora.

BECHARA, Evanildo. 2015. Moderna gramática portuguesa. $38^{\mathrm{a}}$ ed. revista e ampliada, Rio de Janeiro: Nova Fronteira.

BRAGA, Maria Lúcia. 1977. A concordância de número no sintagma nominal no Triângulo Mineiro. Dissertação (Mestrado em Língua Portuguesa) PUC-Rio, Rio de Janeiro.

BRANDÃO, Silvia. 2013. Patterns of agreement within the Noun Phrase. Journal of Portuguese Linguistics, 12: 51-100.

BRANDÃO, Silvia; VIEIRA, Silvia. 2012. Concordância nominal e verbal: contribuições para o debate sobre o estatuto da variação em três variedades urbanas do português. Alfa, 56(3): 1035-1064.

BRANDÃO, Silvia; VIEIRA, Silvia (Orgs). 2013. Ensino de gramática-descrição e uso. $2^{\mathrm{a}}$ ed. São Paulo: Contexto. 
CAMPBELL-KIBLER, Kathryn. 2009. The nature of sociolinguistic perception. Language Variation and Change, 21: 135-156.

CAMPOS, Odette Gertrudes. 2015. Concordância nominal. In: RODRIGUES, Angela; ALVES, Ieda Maria (Orgs.). A construção morfológica da palavra. Gramática do português culto falado no Brasil. São Paulo: Editora Contexto.

CHAVES, R. G. 2014. Princípio de saliência fônica: isso não soa bem. Letrônica, 7(2): 522-550.

COLLISCHONN, Gisela. 1996. O acento em português. In: BISOL. Leda (Org). Introdução a estudos de fonologia do português brasileiro. $3^{\mathrm{a}}$. edição. Porto Alegre: EDIPUCRS.

COSTA, João; FIGUEREIDO SILVA, Maria Cristina. 2006. Nominal and verbal agreement in Portuguese: an argument for Distributed Morphology. In: COSTA, João; FIGUEIREDO SILVA, Maria Cristina (Eds.) Studies on Agreement. Amsterdam/Philadelphia: John Benjamins.

DIAS, Juçá Fialho; FERNANDES, Marisa. 2000. A inter-relação da concordância nominal e da concordância nos predicativos/particípios passivos, sob enfoque da teoria da variação e mudança linguística. Organon, 14(28-29): 115-131.

FERRARI-NETO, José. 2008. Aquisição de Número Gramatical no Português Brasileiro: Processamento de Informação de Interface e Concordância. Tese (Doutorado em Letras). PUC-Rio, Rio de Janeiro.

GUY, Gregory Riordan. 1981. Linguistic Variation in Brazilian Portuguese: Aspects of the Phonology, Syntax and Language History. Tese (Doutorado em Linguística). University of Pennsylvania.

HENRIQUE, Késsia. 2016. Variação linguística e processamento: investigando o papel da distância entre sujeito e verbo na realização da concordância verbal variável no PB. Dissertação (Mestrado em Linguística). UFJF, Juiz de Fora.

LABOV, William. 2003. Some Sociolinguistic Principles. In: PAULSTON, Christina Bratt; Tucker.; TUCKER, G. Richard (Orgs.). Sociolinguistics: The Essential Readings. Oxford: Blackwell.

LOPES, Lays de Oliveira; SCHERRE, Marta Maria. 2014. Influência da saliência fônica no processo de concordância nominal no português falado na zona rural de Santa Leopoldina-ES. In: II Conel- Congresso Nacional de Estudos Linguísticos, Vitória. II CONGRESSO DE ESTUDOS LINGUÍSTICOS- CONEL.

MAGALHÃES, Telma. 2004. A valoração de traços de concordância dentro do DP. DELTA, 20(1), 149-170.

MAGALHAES, Telma; SILVA, Cláudia Roberta. 2014. Sobre a natureza do morfema de pluralidade em português: rediscutindo o domínio da concordância. Veredas, 18: 188-210.

MARCILESE, Mercedes; HENRIQUE, Késsia; AZALIM, Cristina; NAME, Cristina. 2015. Processamento da concordância variável no PB em uma perspectiva experimental. Linguística, 11(1): 118-134.

MARCILESE, Mercedes; RODRIGUES, Erica; AUGUSTO, Marina; HENRIQUE, Késsia. 2017. Efeitos de distância e marcação no processamento da 
concordância verbal variável no PB/ Linear distance and markedness effects in variable subject-verb agreement processing in BP. Revista de Estudos da Linguagem, 25(3), 1291-1325.

MARCILESE, Mercedes; NAME, Cristina; LAIER, Polyana; MAIA, Marina; SCHER, Lilian; GONÇALVEZ, Lydsson; AZALIM, Cristina. Em prep. Aquisição da linguagem e variação linguística: um estudo experimental sobre a concordância nominal variável na fala infantil.

MENDES, Ronald Beline; OUSHIRO, Livia. 2015. Variable Number Agreement in Brazilian Portuguese: An Overview. Language and Linguistics Compass, 9/9: 358-368.

MOLINA, Daniele. Em prep. Aquisição da linguagem e variação linguística: um estudo sobre a flexão verbal variável na aquisição do PB. Tese (Doutorado em Linguística). UFJF, Juiz de Fora.

NICOLAU, Eunice. 1984. A Ausência de Concordância Verbal em Português: uma abordagem sociolingüistica. Dissertação (Mestrado em Linguística). UFMG, Belo Horizonte.

. 1995. A influência da constituição morfológica da forma verbal na ausência de concordância em Português. Revista de Estudos da Linguagem, 3(2): 4167.

OUSHIRO, Livia. 2015. Identidade na pluralidade: avaliação, produção e percepção linguística na cidade de São Paulo. Tese (Doutorado em Semiótica e Linguística Geral). USP, São Paulo.

PÔRTO, Walesca. 2013. A concordância nominal de número: uma pesquisa qualitativa em programas de televisão. Trabalho de Conclusão de Curso (Licenciatura em Letras Português). UnB, Brasília.

RUBIO, Cassio. 2015. Concordância verbal de terceira pessoa do plural no português europeu: variação ou regra semicategórica? Fórum Linguístico, 12(3): 786-806.

SCHERRE, Marta Maria. 1978. A regra de concordância de número no sintagma nominal em português. Dissertação (Mestrado em Língua Portuguesa). PUC-Rio, Rio de Janeiro.

1988. Reanálise da concordância nominal em português. Tese (Doutorado em Linguística). UFRJ, Rio de Janeiro.

1991. A concordância de número nos predicativos e particípios passivos. Organon, 18(5): 52-70.

1994. Aspectos da concordância de número no português do Brasil. Revista Internacional de Língua Portuguesa (RILP) - Norma e Variação do Português. Associação das Universidades de Língua Portuguesa, 12: 37-49.

2005. Doa-se lindos filhotes de poodle - Variação linguística, mídia e preconceito. São Paulo: Parábola.

; NARO, Antony. 2006. Mudança sem mudança: a concordância de número no português brasileiro. Scripta, 9(18): 107-129. 
SILVA, Janaína. 2011. Uma reflexão sobre a concordância nominal na fala capixaba e suas contribuições para o ensino de língua portuguesa. Trabalho de Conclusão de Curso. UFES, Vitória.

SQUIRES, Laura. 2014. Social differences in the processing of grammatical variation. Penn Working Papers in Linguistics 20(2) (Selected Papers from NWAV42). Disponível em: http://repository.upenn.edu/pwpl/vol20/iss2/20.

THORNTON, Rosalind. 1996. Elicited Production. In: McDANIEL, Dana; McKNEE, Cecile; CAIRNS. Helen Smith. (Eds). Methods for assessing children's syntax. Cambridge: MIT Press.

TRASK, Robert Lawrence. 2004. Dicionário de linguagem e linguística. São Paulo: Contexto.

XAVIER, Maria Francisca; MIRA MATEUS, Maria Helena. (Orgs.). 1990. Dicionário de termos linguísticos. Volume II. Lisboa: Edições Cosmos. 